\section{The Medial and Posterior Compression of the Distal Femoral Vein: An Underused Approach to Detect Venous Thrombosis}

Sir,

Venous thromboembolism (VTE) is a common disorder and a major health problem. ${ }^{1}$ Patients with suspected deep vein thrombosis (DVT) are investigated with color Doppler ultrasonography of the entire venous system (whole-leg Duplex). ${ }^{2}$ After a single negative whole-leg Duplex, no further testing is needed, regardless of D-Dimer test. ${ }^{3}$ For this approach, skilled operators and high quality ultrasound equipment are needed. Two-point compression ultrasonography is being used, as an alternative, by an increasing number of emergency physicians; although, there are some limitations, such as missing isolated femoral vein thrombus. ${ }^{4}$

A 67-year man presented to a routine follow-up appointment to a thrombosis clinic. He was diagnosed of pulmonary embolism $(\mathrm{PE})$, femoral vein and popliteal vein thrombosis seven months ago, after prolonged immobility due to a lower limb injury. He was started on edoxaban $60 \mathrm{mg}$ OD for six months. This anticoagulant therapy was suspended one month before the present visit, after confirming absence of thrombosis on a new $\mathrm{CT}$ angiography and a negative whole-leg Duplex. A radiologist, with more than 10 years of experience, performed this follow-up whole-leg Duplex examination.

The physical examination only revealed an asymmetrical right lower limb edema. The main suspicion was post-thrombotic syndrome; butdue to the concerns of DVT after therapy discontinuation, another whole-leg US was performed. This examination was performed by a physician with more than five years of experience in vascular US. The final diagnosis of residual old vein thrombosis was confirmed by the presence of a not fully compressible $(<30 \%)$ hyper-echoic thrombus in the posterior course of the distal femoral vein (Figure 1). The patient after receiving careful advice, decided to continue anticoagulation, and made close follow-up visits in our clinic.

In this patient, since the leg swelling was chronic and did not undergo any worsening, and the ultrasound signs of an hyper-echoic thrombus recanalisation, suggested that it was a residual thrombus. This might be relevant to the higher risk of recurrence. $^{5}$

In this case, it was possible to visualise the thrombus in the posterior aspect of the thigh, and not in the anterior aspect. This is due to the main limitations of the venous examination in the distal anterior thigh (proximal to the adductor hiatus). We found a deep femoral vein with the limitation of compression due to the resis- tance of the vastus medialis muscle; and since it was a non-occlusive clot, augmentation maneuover or Doppler flow studies were of limited help.

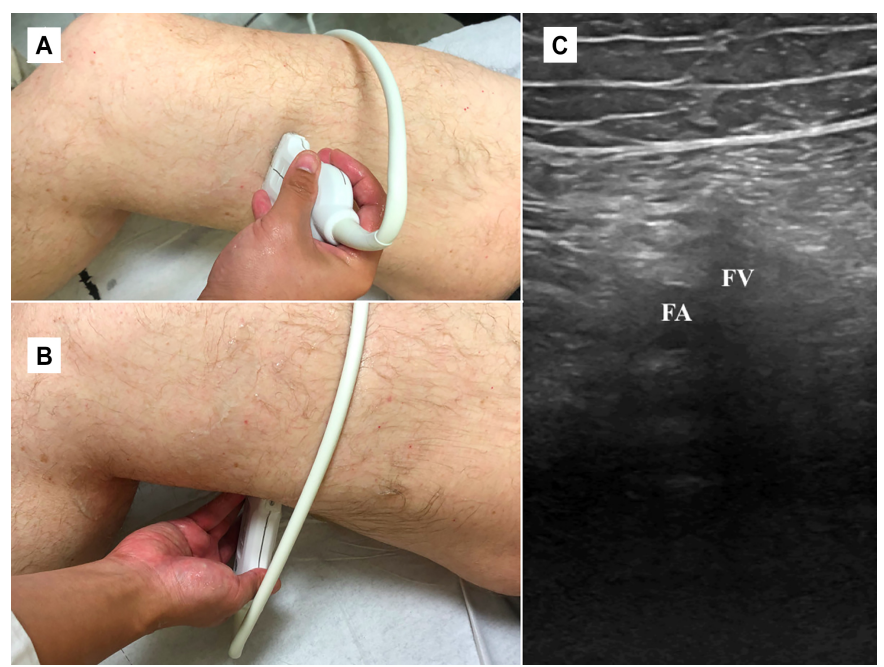

Figure 1: The leg is bent at the knee and rotated outward to expose popliteal fossa. (A) The approximate position of the linear transducer is shown transversely over the distal femoral vein. (B) Approximate position in the proposed posterior approach. (C) Deep vein thrombosis of the distal femoral vein seen in the posterior approach. There is increased echogenicity within the vein and failure of compression.

This posterior approach, although, routinely performed by vascular sonographers, is rarely utilised by other physicians (i.e. emergency physicians or internists), can be easily incorporated while evaluating for the popliteal vein (or artery), being an excellent approach to diagnose distal femoral vein thrombosis, especially when dealing with patients with restricted acoustic windows because of trauma, surgery, cast, skin lesions, etc. Performing this technique, in combination with the previously described compression ultrasound (CUS), it could help not to miss a distal femoral vein thrombosis.

\section{ETHICAL APPROVAL:}

Ethical approval was obtained from concerned quarters.

\section{PATIENT'S CONSENT:}

Written informed consent was obtained from the patient.

\section{CONFLICT OF INTEREST:}

The author declared no conflict of interest.

\section{AUTHOR'S CONTRIBUTION:}

YTC: Collected data, searched the literature, written the case report, and reviewed the final version of the manuscript.

\section{REFERENCES}

1. Christiansen SC, Cannegieter SC, Koster T, Vandenbroucke $\mathrm{P}$, Rosendaal FR. Thrombophilia, clinical factors, and recurrent venous thrombotic events. JAMA 2005; 293(19):2352-61. doi: 10.1001/jama.293.19.2352.

2. Kearon C, Akl EA, Ornelas J, Blaivas A, Jimenez D, Bounameaux $\mathrm{H}$, et al. Antithrombotic therapy for VTE disease: Chest guideline and expert panel report. Chest 2016; 149(2):315-52. doi: 10.1016/j.chest.2015.11.026. 
3. Wells PS, Anderson DR, Bormanis J, Guy F, Mitchell M, Gray $L$, et al. Value of assessment of pretest probability of deepvein thrombosis in clinical management. Lancet 1997; 350(9094):1795-8. doi: 10.1016/S0140-6736(97)08140-3.

4. Adhikari S, Zeger W, Thom C, Fields JM. Isolated deep venous thrombosis: Implications for 2-point compression ultrasonography of the lower extremity. Ann Emerg Med 2015; 66(3):262-6. doi: 10.1016/j.annemergmed.2014. 10.032 .

5. Prandoni P, Vedovetto V, Ciammaichella M, Bucherini E, Corradini S, Enea I, et al. Residual vein thrombosis and serial D-dimer for the long-term management of patients with deep venous thrombosis. Thromb Res 2017; 154:35-41. doi: 10.1016/j.thromres.2017.04.002.
Yale Tung Chen

Department of Emergency Medicine, Ultrasound Division, Hospital Universitario Puerta de Hierro, Madrid, Spain

Correspondence to: Yale Tung Chen, Department of Emergency Medicine, Ultrasound Division, Hospital Universitario Puerta de Hierro, Madrid, Spain

E-mail: yale.tung.chen@gmail.com

Received: September 20,2020; Revised: December 22, 2020; Accepted: February 18, 2021

DOI: https://doi.org/10.29271/jcpsp.2021.11.1389 